\title{
IMPLIKATUR PERCAKAPAN DALAM TRANSAKSI JUAM BELI DI UJUNG SURAMADUMADURA
}

\author{
Annisa Fajar Aprilia \\ (Pendidikan Bahasa Indonesia, Fakultas Keguruan dan Ilmu Pendidikan, \\ Universitas PGRI Adi Buana Surabaya) \\ annisafajaraprilia@gmail.com \\ Ira Eko Retnosari \\ (Pendidikan Bahasa Indonesia, Fakultas Keguruan dan Ilmu Pendidikan, \\ Universitas PGRI Adi Buana Surabaya) \\ ira@unipasby,ac.id
}

\begin{abstract}
This research is based on the occurrence of conversation implicature transactions in buyingand selling transactions at the end of Suramadu Madura. Implications in conversation are conventional forms of implicature and unconventional implicatures. This research is a kind of conversational implicature in a sale and purchase transaction at the end of Suramadu Madura. This method is a descriptive method. The purpose of this study is to describe the pattern of systematic, factual and accurate relationships between the phenomena investigated. Implicit in the sale and purchase transaction at the end of Suramadu Madura has two types, namely: conventional implicature and unconventional implicature. Conventional Implication is a type of implicature derived from the meaning of words, not from the principle of conversation. Whereas nonconventional implicatures are the implications of pragmatics implicit in conversation. In communication, speech always presents functional functions and in conversation, intentions implied.
\end{abstract}

Keywords: conversation implicatur, conventional implicatures, unconventional implicatures

\section{PENDAHULUAN}

Implikatur percakapan dibagi menjadi dua jenis, yakni: implikatur percakapan konvensional dan implikatur nonkonvensional. Implikatur konvensional adalah jenis implikatur yang diperolah langsung dari makna kata, bukan dari prinsip percakapan. Sedangkan implikatur nonkonvensional ialah implikasi pragmatik yang tersirat di dalam suatu percakapan. Di dalam komunikasi, tuturan selalu menyajikan suatu fungsi pragmatik dan di dalam tuturan percakapan tersebut terimplikasi suatu maksud yang tersirat.

Kehadiran

Jembatan

Suramadu diharapkan dapat berfungsi sebagai jembatan kesetaraan. Atau jika boleh ditambahkan, mampu menjembatani segala hal, dari sosial-budaya, hingga ekonomi dan politik. Namun bagi warga Madura, deretan harapan itu tak sepenuhnya dapat terwujud. Dampak signifikan dari geliat ekonomi dan kemajuan di Madura atau orang-orang Madura secara umum sebelum dan sesudah era Suramadu. Di ujung Suramadu Madura, masyakarat Madura membuka deretan kios 
kecil, rumah toko (ruko) dan warung kopi untuk melepas lelah warga sekitar yang ingin berpariwisata di Madura. Sebaliknya di sisi Madura selepas pintu keluar jembatan, pemandangan bentangan alam kosong masih tampak. Bahkan beberapa kilometer masih terlihat lahan sawah yang luas dan sebagian gersang. Hanya tampak beberapa kios warga penjual oleholeh khas Madura, itu pun tidak tertata rapi. Kuliner khas Madura yang menjadi buruan para pelancong adalah bebek Sinjai Madura.

Berdasarkan uraian di atas, implikatur daalam percakapan transaksi jual beli di ujung suramadu Madura, menggunakan teori implikatur percakapan Grace yang membagi dua implikatur percakapan konvensional dan nonkonvensional.

\section{METODE PENELITIAN}

Metode yang digunakan dalam penelitian ini adalah pendekatan kualitatif. Sebuah pendekatan penelitian yang bertujuan untuk memberikan atau menjabarkan suatu keadaan atau fenomena yang terjadi saat ini dengan menggunakan prosedur ilmiah untuk menjawab masalah secara aktual (Sugiyono,2015:207). Metode yang digunakan pada penelitian ini adalah metode deskriptif. Tujuan dari penelitian deskriptif ini, untuk membuat gambaran atau lukisan secara sistematis, faktual dan akurat mengenai fakta-fakta, sifat-sifat serta hubungan antar fenomena yang diselidiki.

Teknik pengumpulan data menggunakan teknik dokumentasi yaitu dengan cara merekam video dan suara secara langsung melalui telefon seluler proses terjadinya transaksi jual beli yang ada di sepanjang jalan Suramadu Madura. Prosedur Pengumpulan Data (1) Mengobservasi dengan cara melakukan kunjungan di Ujung Suramadu Madura,

Mewawancara kepada penjual di Ujung Suramadu Madura tentang proses transaksi jual beli yang dilakukan setiap hari, kapan mendirikan kios di ujung Suramadu Madura. (3) Mendokumentasi dengan cara merekam percakapan penjual dan pembeli dalam melakukan transaksi jual beli dengan tawar-menawar dengan merekam secara langsung, Mentranskip hasil rekaman suara antara penjual dan pembeli saat melakukan transaksi jual beli, (5) Mengelompokkan data yang telah terkumpul, (6) Mengode pada jenis pertanyaan yang diajukan. Seluruh kode yang ditentukan untuk setiap jawaban, disusun dalam buku kode. Implikatur percakapan konvensional dikode (I.K) dan implikatur nonkonkonvensional dikode (I.NK).

Hal ini tampak pada Data berikut.

\section{1) Implikatur Konvensional}

Implikatur konvensional adalah implikatur yang diperolah langsung dari makna kata, bukan dari prinsip percakapan. Tuturan berikut mengandung implikatur konvensional.

Peristiwa Tutur 1

Hari, tanggal : Kamis, 9

Agustus 2018 Waktu

$$
\text { : } 10.40
$$

Penjual : Batik Sumenep

(1) $\mathrm{Pb}:$ permisi pak

$$
\mathrm{Pj} \quad \text { : silahkan }
$$


$\mathrm{Pb} \quad$ : ini batik asli

Madura tah pak?

$\mathrm{Pj} \quad$ : iya mbak, ini batik

Sumenep.

(I/Pj.BS/K1)

Peristiwa tutur 1 , terjadi di tempat penjual batik khas Madura. Implikatur konvensional, terjadi pada kalimat yang diucapkan pembeli yaitu "ini batik asli Madura ya pak?". Tuturan tersebut mengimplikasikan bahwa $\mathrm{Pb}$ sudah mengetahui batik tersebut asli, hanya saja $\mathrm{Pb}$ meyakinkan untuk bertanya kembali kepada $\mathrm{Pj}$.

Percakapan tersebut terjadi hari Kamis, 9 Agustus 2018 pukul 10.40 WIB di Ujung Suramadu Madura. Penggunaaan bahasa yang digunakan ialah, bahasa Indonsia. Percakapan ini berlangsung di Ujung Suramadu Madura.

Pada I.K1, Pb menanyakan bahwa kain yang hendak dibelinya merupakan kain batik asli Madura. $\mathrm{Di}$ samping itu, tujuan $\mathrm{Pb}$ menciptakan IP agar Pj mengetahui bahwa kain itu merupakan aslibatik Madura. Dari hal tersebut, dapat diketahui bahwa IP tersebut langsung ditanggapi oleh (Pj.BS) $\mathrm{Pj}$ dengan mengatakan "iya mbak, ini batik Sumenep”. IP Pb dan Pj dapat dipahami bersama berdasarkan pengetahuan tentang transaksi jual beli yang dilakukan di pasar.

(2) $\mathrm{Pb}$ : ini batik cetak atau batik tulis ya pak kira-kira?

$\mathrm{Pj}$ : ya macem-macem mbak. Ada yang tulis dan ada yang cetak.

(I/Pj.BS/K2)

Implikatur konvensional juga terdapat pada kalimat "ini batik cetak atau batik tulis ya pak kira-kira?". Tuturan tersebut, mengimplikasikan bahwa $\mathrm{Pb}$ belum mengetahui perbedaan antara batik tulis dan batik cetak.

Percakapan tersebut terjadi hari Kamis, 9 Agustus 2018 pukul 10.40 WIB di Ujung Suramadu Madura. Penggunaaan bahasa yang digunakan ialah, bahasa Indonsia. Percakapan ini berlangsung di Ujung Suramadu Madura.

Pada I.K2, Pb menanyakan bahwa kain yang hendak dibelinya merupakan kain batik cetak, atau batik tulis. Di samping itu, tujuan $\mathrm{Pj}$ menciptakan IP agar $\mathrm{Pb}$ mengetahui bahwa kain yang ia jual ada bermacam-macam. Dari batik tulis, hingga batik cetak. Dari hal tersebut, dapat diketahui bahwa IP tersebut langsung ditanggapi oleh $\mathrm{Pj}$ dengan mengatakan "ya macemmacem mbak. Ada yang tulis dan ada yang cetak". IP Pbdan Pj dapat dipahami bersama berdasarkan pengetahuan tentang transaksi jual beli yang dilakukan di pasar.

Jadi, dengan mempertimbangkan daya ilokuusi sebuah IP akan diketahui apa yang menjadi tujuan $\mathrm{Pb}$ dan (Pj.BS) Pj ketika mengeluarkan tuturannya. Dari aspek-aspeksituasi ujar seperti penutur, penutur, konteks, tujuan, tindak ilokusi dan tuturan dapat dikatakan bahwa IP $\mathrm{Pb}$, "ini batik Madura asli ya pak?”. Mengimplikasikan bahwa IP (Pj.BS) Pj menunjukkan bahwa itu batik asli Madura kepada $\mathrm{Pb}$ dan batik yang $\mathrm{Pj}$ jual, ada bermacammacam. Dari batik tulis, hingga batik cetak.

Peristiwa Tutur 2

Hari, tanggal : Kamis, 9

Agustus 2018Waktu

$$
\text { : } 11.15
$$

Penjual : Penjual Boneka

(3) $\mathrm{Pb}$ : siang buk 
$\mathrm{Pj}$ : iya dek, ayo

silahkan dipilih! $\mathrm{Pb}$ :

bonekanya bagus buk

yang ini!

Harganya berapa?

$\mathrm{Pj}$ : harganya 40.000 dek.

Boleh nawar kok. $\mathrm{Pb}:$ wih.. mahalnya bu 20.000 ajah ya. Langsung bungkus 1 (I/Pj.BA/K3)

Peristiwa tutur 2 pada I.K3, terjadi di tempat penjual boneka. Implikatur konvensional, terjadi pada kalimat yang diucapkan pembeli yaitu "wih.. mahalnya bu 20.000 ajah ya. Langsung bungkus l'. Tuturan tersebut mengimplikasikan bahwa $\mathrm{Pb}$ merasa harga yang ditawarkan $\mathrm{Pj}$ sangat mahal dan langsung menawarnya dengan harga 20.000.

Percakapan tersebut terjadi hari Kamis, 9 Agustus 2018 pukul 11.15 WIB di Ujung Suramadu Madura. Penggunaaan bahasa yang digunakan ialah, bahasa Indonsia. Percakapan ini berlangsung di Ujung Suramadu Madura.

Pada I.K3, Pb menawar harga boneka yang hendak dibelinya. Di samping itu tujuan (Pj.BA) Pj menciptakan IP agar $\mathrm{Pb}$ mengetahui berapa harga boneka tersebut. Dari hal tersebut, dapat diketahui bahwa IP tersebut langsung ditanggapi oleh $\mathrm{Pb}$ dengan mengatakan "wih.. mahalnya bu? 20.000 ajah ya. Langsung bungkus 1". IP $\mathrm{Pb}$ dan (Pj.BA) Pj dapat dipahami bersama berdasarkan pengetahuan tentang transaksi jualbeli yang dilakukan di pasar.

(4) $\mathrm{Pj} \quad$ : waduh.. gak bisa mbak.

$\mathrm{Pb}$ : yaudah wes 25.000 pas bu.Pj : yaudah buat penglaris (I/Pj.BA/K4)

Implikatur konvensional juga terdapat pada kalimat "waduh.. gak bisa mbak.". Tuturan tersebut, mengimplikasikan bahwa $\mathrm{Pj}$ merasa belum balik modal dengan harga 20.000 yang telah ditawar sebelumnya oleh $\mathrm{Pb}$. Sehingga, (Pj.BA) $\mathrm{Pj}$ belum mengiyakan tawaran harga 20.000 yang telah ditawarkan oleh $\mathrm{Pb}$.

Percakapan tersebut terjadi hari Kamis, 9 Agustus 2018 pukul 11.15 WIB di Ujung Suramadu Madura. Penggunaaan bahasa yang digunakan ialah, bahasa Indonsia. Percakapan ini berlangsung di Ujung Suramadu Madura.

Pada I.K4, Pj belum menyetujui harga yang ditawarkan oleh pembeli, karna menurut $\mathrm{Pj}$ masih belum balik modal. Di samping itu tujuan (Pj.BA) $\mathrm{Pj}$ menciptakan IP agar $\mathrm{Pb}$ menawar kembali dengan harga yang sedikit dinaikan. Dari hal tersebut, dapat diketahui bahwa IP tersebut langsung ditanggapi oleh pb dengan mengatakan "yaudah wes 25.000 pas bu”. IP $\mathrm{Pb}$ dan (Pj.BA) $\mathrm{Pj}$ dapat dipahami bersama berdasarkan pengetahuan tentang transaksi jual beli yang dilakukan di pasar.

Jadi, dengan mempertimbangkan daya ilokusi sebuah IP akan diketahui apa yang menjadi tujuan $\mathrm{Pb}$ dan ( $\mathrm{Pj} . \mathrm{BA}) \mathrm{Pj}$ ketika mengeluarkan tuturannya. Dari aspek-aspek situasi ujar seperti penutur, penutur, konteks, tujuan, tindak ilokusi dan tuturan dapat dikatakan bahwa IP $\mathrm{Pb}$, "wih.. mahalnya bu 20.000 ajah ya. Langsung bungkus 1". Tuturan tersebut 
mengimplikasikan bahwa $\mathrm{Pb}$ merasa harga yang ditawarkan $\mathrm{Pj}$ sangat mahal dan langsung menawarnya dengan harga 20.000 - Implikatur konvensional juga terdapat pada kalimat "yaudah wes 25.000 pas bu". Tuturan tersebut mengimplikasikan bahwa $\mathrm{Pj}$ mengiyakantawaran $\mathrm{Pb}$ dengan harga 25.000 karena dirasa dengan harga $25.000 \mathrm{~Pb}$ sudah mendapatkan keuntungan.

\section{2.}

\section{Nonkonvensional}

Implikatur nonkonvensional adalah implikasi pragmatik yang tersirat di dalam suatu percakapan. Di dalam komunikasi, tuturan selalu menyajikan suatu fungsi pragmatik dan di dalam tuturan percakapan tersebut terimplikasi suatu maksud yang tersirat.

Peristiwa Tutur 3

Hari, tanggal : Kamis, 9

Agustus 2018Waktu

$$
\text { : } 10.40
$$

Penjual : Batik Sumenep

(1) $\mathrm{Pb}$ : harga berapa pak yang ini? $\mathrm{Pj}$ : oh.. kalau yang itu murah mbak, itu batik cetak harganya 100.000

(I/Pj.BS/NK1)

Peristiwa tutur 1 pada I.NK1, terjadi di tempat penjual batik khas Madura. Implikatur nonkonvensional, terjadi pada kalimat yang diucapkan penjual yaitu "oh.. kalau yang itu murah mbak, itu batik cetak harganya 100.000". Tuturan tersebut mengimplikasikan bahwa batik yang $\mathrm{Pj}$ jual memiliki harga yang bermacam- macam. Ada yang harga mahal dan ada pula yang murah. Salah satu batik yang murah menurut $\mathrm{Pj}$ adalah batik cetak, sedangkan batik tulis, harganya mahal. Implikasi dari implikatur nonkonvensional ialah batik tulis harganya lebih mahal dari batik tulis.

Percakapan tersebut terjadi hari Kamis, 9 Agustus 2018 pukul 10.40 WIB di Ujung Suramadu Madura. Penggunaaan bahasa yang digunakan ialah, bahasa Indonsia. Percakapan ini berlangsung di Ujung Suramadu Madura.

Pada I.NK1, Pj mengatakan bahwa batik cetak yang ia jual harganya murah, yaitu 100.000. Di samping itu, tujuan Pj menciptakan IP agar $\mathrm{Pb}$ mengetahui bahwa kain batik yang ia jual, ada bermacammacam harga. Salah satunya batik cetak yang dijual murah dengan harga 100.000, sedangkan batik tulis dijual sedikit mahal. Dari hal tersebut, dapat diketahui bahwa IP tersebut langsung ditanggapi oleh (Pj.BS) Pj dengan mengatakan "oh itu yang murah mbak. Itu batik cetak harganya 100.000". IP Pb dan $\mathrm{Pj}$ dapat dipahami bersama berdasarkan pengetahuan tentang transaksi jual beli yang dilakukan di pasar.

(2) $\mathrm{Pb}$ : kalau ini pak?

$\mathrm{Pj}$ : itu yang paling bagus dek! Harganya350.000

$\mathrm{Pb}$ :kalau harga yang bisa turun yang mana?(I/Pj.BS/NK2)

Peristiwa tutur 1 pada I.NK2, terjadi di tempat penjual batik khas Madura. Implikatur nonkonvensional, terjadi pada kalimat yang diucapkan penjual yaitu "itu yang paling bagus dek. Harganya 350.000". Tuturan tersebut mengimplikasikan bahwa batik yang biasa saja atau tidak bagus harganya di bawah 350.000 . Implikasi dari implikatur nonkonvensional ialah batik tulis 
harganya lebih mahal dari batik tulis.

Percakapan tersebut terjadi hari Kamis, 9 Agustus 2018 pukul 10.40 WIB di Ujung Suramadu Madura. Penggunaaan bahasa yang digunakan ialah, bahasa Indonsia. Percakapan ini berlangsung di Ujung Suramadu Madura. Pada I.NK2, Pj mengatakan bahwa batik yang paling bagus harganya 350.000 sedangkan yang biasa harganya di bawah 350.000. Di samping itu, tujuan $\mathrm{Pj}$ menciptakan IP agar $\mathrm{Pb}$ mengetahui bahwa kain batik yang ia jual, ada bermacammacam harga. Salah satunya batik cetak yang dijual murah dengan harga 100.000, sedangkan batik tulis dijual sedikit mahal. Dari hal tersebut, dapat diketahui bahwa IP tersebut langsung ditanggapi oleh (Pj.BS) Pj dengan mengatakan "itu yang paling bagus dek.Harganya 350.000". IP $\mathrm{Pb}$ dan $\mathrm{Pj}$ dapat dipahami bersama berdasarkan pengetahuan tentang transaksi jual beli yang dilakukan di pasar.

(3) $\mathrm{Pb}$ : kalau harga yang bisa turun yang mana? $\mathrm{Pj}$ : yang sebelah pojok itu harganya sama

200.000 sетиа.

$\mathrm{Pb}:$ apa

boleh kurang

pak?

(I/Pj.BS/NK3

)

Peristiwa tutur 1 pada I.NK3, terjadi di tempat penjual batik khas Madura. Implikatur nonkonvensional, terjadi pada kalimat yang diucapkan penjual yaitu "yang sebelah pojok itu harganya sama 200.000 semua".

Tuturan tersebut

mengimplikasikan bahwa batik yang bukan di sebelah sana harganya di atas atau di bawah 200.000. Implikasi dari implikatur nonkonvensional ialah batik pada bagian tertentu harganya bisa di bawah atau di atas200.000.

Percakapan tersebut terjadi hari Kamis, 9 Agustus 2018 pukul 10.40 WIB di Ujung Suramadu Madura. Penggunaaan bahasa yang digunakan ialah, bahasa Indonsia. Percakapan ini berlangsung di Ujung Suramadu Madura.

Pada I.NK3, Pj mengatakan bahwa batik pada bagian tertentu harganya bisa di bawah atau di atas 200.000. Di samping itu, tujuan $\mathrm{Pj}$ menciptakan IP agar $\mathrm{Pb}$ mengetahui bahwa kain batik yang ia jual, pada tempat tertentu harganya di atas atau di bawah 200.000. Dari hal tersebut, dapat diketahui bahwa IP tersebut langsung ditanggapi oleh (Pj.BS) $\mathrm{Pj}$ dengan mengatakan "yang sebelah pojok itu harganya sama 200.000 semua". IP Pb dan Pj dapat dipahami bersama berdasarkan pengetahuan tentang transaksi jual beli yang dilakukan di pasar.

Jadi, dengan mempertimbangkan daya ilokusi sebuah IP akan diketahui apa yang menjaditujuan $\mathrm{Pb}$ dan ( $\mathrm{Pj} . \mathrm{BS}) \mathrm{Pj}$ ketika mengeluarkan tuturannya. Di dalam komunikasi, tuturan selalu menyajikan suatu fungsi pragmatik dan di dalam tuturan percakapan tersebut terimplikasi suatu maksud yang tersirat. Tuturan dapat dikatakan bahwa IP $\mathrm{Pj}$, "oh.. kalau yang itu murah mbak, itu batik cetak harganya 100.000". Tuturan tersebut mengimplikasikan bahwa batik yang $\mathrm{Pj}$ jual memiliki harga yang 
bermacam-macam. Ada yangharga mahal dan ada pula yang murah. Salah satu batik yang murah menurut $\mathrm{Pj}$ adalah batik cetak, sedangkan batik tulis, harganya mahal. IP pada I.NK2, dikatakan oleh $\mathrm{Pj}$ "itu yang paling bagus dek. Harganya 350.000". Tuturan tersebut mengimplikasikan bahwa batik yang biasa saja atau tidak bagus harganya di bawah 350.000. Implikasi dari implikatur nonkonvensional ialah batik tulis harganya lebih mahal dari batik tulis. Untuk IP pada I.NK3, dikatakan oleh $\mathrm{Pj}$ "yang sebelah pojok itu harganya sama 200.000 sетиа". Tuturan tersebut mengimplikasikan bahwa batik yang bukan di sebelah sana harganya di atas atau di bawah 200.000. Implikasi dari implikatur nonkonvensional ialah batik pada bagian tertentu harganya bisa di bawah atau di atas200.000.

Peristiwa Tutur 4v

Hari, tanggal : Kamis, 9

Agustus 2018Waktu

$$
\text { : } 11.15
$$

Penjual : Penjual Boneka

(4) $\mathrm{Pb}$ : yah.. saya bawa uang pas bu. 15.000! Apa boleh harganya 15.000 ?

$\mathrm{Pj}$ : yaudah bawa ajah dek

$\mathrm{Pb}$ : terima kasih buk

$\mathrm{Pj}$ : iya sebentar saya bungkus dulu. (I/Pj.BA/NK4)

Peristiwa tutur 2 pada I.NK4, terjadi di tempat penjual boneka. Implikatur nonkonvensional, terjadi pada kalimat yang diucapkan pembeli yaitu "yaudah bawa ajah dek". Tuturan tersebut mengimplikasikan bahwa $\mathrm{Pj}$ merasa kasihan melihat $\mathrm{Pb}$ membawa uang pas. Jika harga yang ditawarkan mahal, $\mathrm{Pj}$ takut tidak jadi membeli karena tidak ada pembeli. Implikasi dari implikatur nonkonvensional ialah $\mathrm{Pj}$ merasa kasihan melihat $\mathrm{Pb}$ membawa uang pas. Jika harga yang ditawarkan mahal, Pj takut tidak jadi membeli karena tidak ada pembeli.

Percakapan tersebut terjadi hari Kamis, 9 Agustus 2018 pukul 11.15 WIB di Ujung Suramadu Madura. Penggunaaan bahasa yang digunakan ialah, bahasa Indonsia. Percakapan ini berlangsung di Ujung Suramadu Madura.

Pada I.NK4, Pj Pj merasa kasihan melihat $\mathrm{Pb}$ membawa uang pas. Jika harga yang ditawarkan mahal, Pj takut tidak jadi membeli karena tidak ada pemasukan pada hari itu. Di samping itu, tujuan $\mathrm{Pj}$ menciptakan IP agar $\mathrm{Pb}$ menerima harga yang ditawarkan $\mathrm{Pb}$. Dari hal tersebut, dapat diketahui bahwa IP tersebut langsung ditanggapi oleh $\mathrm{Pb}$ dengan mengatakan "yaudah bawa ajah dek". IP Pb dan Pj dapat dipahami bersama berdasarkan pengetahuan tentang transaksi jual beli yang dilakukan di pasar.

$$
\text { Jadi, }
$$
dengan mempertimbangkan daya ilokusi sebuah IP akan diketahui apa yang menjadi tujuan $\mathrm{Pb}$ dan ( $\mathrm{Pj} . \mathrm{BA}) \mathrm{Pj}$ ketika mengeluarkan tuturannya. Di dalam komunikasi, tuturan selalu menyajikan suatu fungsi pragmatik dan di dalam tuturan percakapan tersebut terimplikasi suatu maksud yang tersirat. Tuturan dapat dikatakan bahwa IP $\mathrm{Pj}$, "yaudah bawa ajah dek". Tuturan tersebut mengimplikasikan bahwa $\mathrm{Pj}$ merasa kasihan melihat $\mathrm{Pb}$ membawa uang pas. Jika harga yang ditawarkan mahal, $\mathrm{Pj}$ takut tidak jadi membeli karena tidak ada pemasukan pada hari itu. 


\section{SIMPULAN}

Dari hasil penelitian yang dilakukan, dapat disimpulkan bahwa implikatur percakapan dalam transaksi jual beli di Ujung Suramadu Madura menghasilkan implikatur konvensional dan implikatur nonkonvensional. Percakapan antara penjual dan pembeli menggunakan bahasa Indonesia. Dalam percakapan tersebut, tersirat makna yang dihasilkan untuk penjual menarik pembeli.

\section{SARAN}

Berdasarkan simpulan yang telah diuraikan, saran yang dapat dikemukakan adalah sebagai berikut.

(1) Bagi pembaca, hasil penelitian ini dapat digunakan untuk mengetahui implikatur percakapan dalam ilmu pragmatik. (2) Bagi masyarakat, hasil penelitian ini dapat digunakan untuk menambah wawasan bagi pengguna bahasa untuk menggunakan percakapan dalam transaksi jual beli. (3) Dalam peminat pragmatik, diharapkan dapat memperdalam implikasi pragmatis yang terdapat dalam percakapn transaksi jual beli di pasar.

\section{DAFTAR PUSTAKA}

Chaer, Abdul. 2009.

Psikolinguistik. Jakarta:Rineka

Cipta

Grice (dalam Nadar, 2008:28) membagiimplikatur

menjadi dua macam, yaitu

implikatur

konvensional dan

implikaturnonkonvensional

(implikatur percakapan)

Gunarwam, Asim. 2007.

Pragmatik: Teori dan Kajian

Nusantara. Jakarta:

Universitas Atmajaya

Jumanto. 2017 edisi 2, Dunia Linguistik Tak Selebar Daun Kelor. Yogyakarta: Morfalingua.

Nadar, Fransicus Xaverious. 2008. Pragmatik dan Penelitian Pragmatik. Yogyakarta: GrahaIlmu

Sugiyono. 2015. Metode

Penelitian Kualitatif

Kuantitatif dan $R \& D$.

Bandung:CV.Alfabet.

Wijana, I Dewa Putu. 1996.

Dasar-dasar Pragmatik.

Yogyakarta: Andi.Verhaar. 2012. Asas-Asas Linguistik

Umum. Yogyakarta:

Gadjah Mada University

Press.

Yule, George. 2006. Pragmatik

(terjemahan). Yogyakarta: Pustaka

Pelajar 